\title{
The inflammatory potential of diet and ovarian cancer risk: results from two prospective cohort studies
}

\author{
Fred K Tabung ${ }^{\star, 1,2}$, Tianyi Huang ${ }^{1,3}$, Edward L Giovannucci ${ }^{1,2,3,4}$, Stephanie A Smith-Warner ${ }^{1,2}$, \\ Shelley S Tworoger ${ }^{2,3,4}$ and Elizabeth M Poole 3,4 \\ ${ }^{1}$ Department of Nutrition, Harvard T.H. Chan School of Public Health, Boston, MA 02115, USA; ${ }^{2}$ Department of Epidemiology, \\ Harvard T.H. Chan School of Public Health, Boston, MA 02115, USA; ${ }^{3}$ Channing Division of Network Medicine, Brigham and \\ Women's Hospital, Boston, MA 02115, USA and ${ }^{4}$ Department of Medicine, Harvard Medical School, Boston, MA 02115, USA
}

Background: We used a food-based empirical dietary inflammatory pattern (EDIP) score to investigate whether diets with higher inflammatory potential are associated with increased ovarian cancer risk.

Methods: We followed 186314 women in the Nurses' Health Study and Nurses' Health Study-II, from 1984 to 2013, to examine associations between EDIP scores and ovarian cancer risk, using Cox regression analyses.

Results: During 3454514 person-years of follow-up, 989 ovarian cancer cases were identified. In pooled multivariable-adjusted analyses, higher EDIP scores (more pro-inflammatory diets) were not significantly associated with ovarian cancer risk (HR quintile5vs 1 0.99; 95\% Cl: $0.80-1.22 ; P$-trend=0.97). Similarly, we found no evidence of heterogeneity by histologic subtype $(P$ heterogeneity $=0.52$ ) or by tumour aggressiveness ( $P$-heterogeneity $=0.63$ ).

Conclusions: In contrast with two previous case-control studies that found a positive association between a literature-derived nutrient-based dietary inflammatory index and ovarian cancer risk, our prospective analyses using a food-based score observed no evidence of an association.

Ovarian cancer has a high fatality rate (Siegel et al, 2017), yet few modifiable risk factors have been identified (Faber et al, 2013; Tworoger and Huang, 2016). Previous research suggests that dietary factors could influence ovarian cancer risk but no specific dietary factors or dietary patterns have consistently been associated with risk (Crane et al, 2014; Xie et al, 2014). Studies have found significantly higher pre-diagnosis levels of C-reactive protein (CRP), various interleukins (e.g., IL-6) and tumour necrosis factor alpha (TNF- $\alpha$ ), among other markers, in ovarian cancer cases compared to non-cases (Poole et al, 2013a; Zeng et al, 2016). We hypothesise that diets with higher inflammatory potential may influence ovarian cancer risk.
Two case-control studies that assessed dietary inflammatory potential using a literature-derived nutrient-based dietary inflammatory index (Shivappa et al, 2016; Peres et al, 2017) reported that higher index scores were associated with higher risk of ovarian cancer. However, these findings may have been influenced by reverse causation due to differential use of nutritional supplements, which influence the score, based on case-control status (Shivappa et al, 2014; Peres et al, 2017). To elucidate the role of dietary inflammatory potential in ovarian cancer risk, we investigated the association between an empirical food-based dietary inflammatory pattern score (Tabung et al, 2016), with ovarian cancer risk in two prospective cohort studies.

*Correspondence: Dr FK Tabung; E-mail: ftabung@hsph.harvard.edu

Received 25 April 2017; revised 27 June 2017; accepted 4 July 2017; published online 3 August 2017

(C) 2017 Cancer Research UK. All rights reserved 0007-0920/17 


\section{MATERIALS AND METHODS}

Study population. The Nurses' Health Study (NHS) and Nurses' Health Study-II (NHS-II) are ongoing prospective cohorts established in 1976 and 1989, respectively. The NHS $(n=121700)$ enrolled female registered nurses aged 30-55 years, while the NHS-II $(n=116429)$ enrolled younger female registered nurses 25-42 years (Willett et al, 1985). For the current study, we excluded participants who reported menopause due to pelvic irradiation, any cancer other than nonmelanoma skin cancer, or bilateral oophorectomy; who did not complete a food frequency questionnaire (FFQ) during follow-up; or who had implausible values for total energy intake $\left(<500\right.$ or $\left.>3500 \mathrm{kcal} \mathrm{d}^{-1}\right)$ at study entry. This resulted in the inclusion of 89034 women from the NHS and 97280 women from the NHS-II for a total of 186314 participants. The Institutional Review Board at Brigham and Women's Hospital approved this study.

Calculation of empirical dietary inflammatory pattern scores. Dietary intake was assessed in 1984, 1986, and every 4 years thereafter in the NHS. In the NHS-II, similar FFQs were initially administered in 1991 and subsequently every 4 years (Willett et al, 1985; Feskanich et al, 1993). The development of the empirical dietary inflammatory pattern (EDIP) score has been previously described (Tabung et al, 2016). The goal was to empirically create a score for overall inflammatory potential of whole diets defined using food groups. The investigators entered 39 pre-defined food groups (Hu et al, 1999) in reduced rank regression models followed by stepwise linear regression analyses to identify a dietary pattern most predictive of three plasma inflammation markers, IL6, CRP, and TNF $\alpha$-receptor 2 . The EDIP score is the weighted sum of 18 food groups, with higher (more positive) scores indicating proinflammatory diets and lower (more negative) scores indicating anti-inflammatory diets (Tabung et al, 2016, 2017).

Ascertainment of ovarian cancer. Information about new ovarian cancer diagnoses was collected on each biennial questionnaire and confirmed by medical records abstraction or by linking to the appropriate cancer registry or the National Death Index (Stampfer et al, 1984).

Statistical analysis. Person-years of follow-up were calculated from the return date of the first completed FFQ until the earliest date of: death, pelvic irradiation, bilateral oophorectomy, any cancer diagnosis (except non-melanoma skin cancer), or end of follow-up (NHS: June 2012; NHS-II: June 2013). EDIP scores were calculated as the cumulative average score from all prior reports up to the start of each 2-year follow-up interval, to best represent habitual long-term dietary intake and reduce within-person variation. We used Cox proportional-hazards regression models with time-varying covariates to estimate hazard ratios (HR) and 95\% confidence intervals (CI) for EDIP scores in relation to ovarian cancer risk, with the lowest EDIP quintile as the reference group. Early symptoms of undiagnosed ovarian cancer may alter habitual diet intake; therefore, we used a 2-year lag between dietary assessment and ovarian cancer incidence as the main analytic approach. Multivariable models were adjusted for biennially updated covariates listed in the footnotes to Tables 2 and 3. For analyses of linear trend across EDIP quintiles, we used the continuous residual-adjusted EDIP score.

Duplication method cause-specific Cox regression models (Wang et al, 2016) were used in the pooled analysis to examine whether the association of EDIP scores differed by ovarian tumour histologic subtypes (serous/poorly differentiated $v s$ non-serous) and by tumour aggressiveness (death due to ovarian cancer within 3 years of diagnosis $v s$ not) (Poole et al, 2013b). In subgroup analyses, we stratified models in the pooled data by potential effect modifiers (listed in Supplementary Table 1) selected a priori, based on findings in previous studies (Shivappa et al, 2016; Peres et al, 2017).

In a sensitivity analysis, we derived an alternative dietary pattern that specifically predicted concentrations of plasma CRP, the inflammation marker most consistently associated with higher ovarian cancer risk (Poole et al, 2013a; Zeng et al, 2016). Further, we replaced cumulatively averaged EDIP score with baseline EDIP score or with recently updated EDIP score, to test the influence of dietary intake in the distant past or in the recent past, respectively. All analyses were performed using SAS software, version 9.4 for UNIX (SAS Institute, NC, USA), at a two-sided $P$-value of 0.05 .

\section{RESULTS}

We documented 989 cases of incident ovarian cancer (731 in NHS and 258 in NHS-II) over 3454514 person-years of follow-up. Over the entire follow-up period in both cohorts (28 years in NHS and 22 years in NHS-II), women consuming the most pro-inflammatory diets (EDIP quintile 5) reported lower physical activity, lower average duration of breastfeeding, higher waist-to-hip ratio, and higher BMI than those consuming the most anti-inflammatory diets (quintiles 1) (Table 1).

In pooled multivariable-adjusted analyses, dietary inflammatory potential was not associated with ovarian cancer risk. The HR for women in the highest compared to the lowest EDIP quintile was 0.99; 95\% CI: $0.80,1.22$; P-trend, 0.97 . The association did not differ by cohort: the HRs comparing extreme index quintiles were: 1.03; 95\% CI: $0.80,1.32$; $P$-trend, 0.46 in the NHS and 0.93; 95\% CI: $0.63,1.39$; P-trend, 0.37 in the NHS-II (Table 2). In subtype analyses, we found no evidence that the inflammatory potential of diet influenced ovarian cancer risk differentially by subtype $(P$-heterogeneity $=0.52)$ or by tumour aggressiveness $(P$-heterogeneity $=0.63)$ (Table 3$)$.

Similarly, there were no substantial associations in strata of the potential effect modifiers, and no evidence for interaction (Supplementary Table 1). The findings from our sensitivity analysis of the CRP-specific inflammatory diet score were consistent with the null results for the overall EDIP score (Supplementary Table 2). Similarly, we found no association between EDIP scores and ovarian cancer risk using dietary intake assessed at baseline only or with recently assessed diet (Supplementary Table 3).

\section{DISCUSSION}

In this large prospective study, we used an empirically derived food-based index to assess dietary inflammatory potential and investigated its association with ovarian cancer risk. Our results revealed no statistically significant associations between the inflammatory potential of diet and ovarian cancer risk; a finding that did not differ by tumour subtype or aggressiveness. Also, we found no difference in the association by BMI category, menopausal status, oral contraceptive use, parity or family history of breast or ovarian cancer.

Two previous case-control studies that examined the association between a literature-derived nutrient-based dietary inflammatory index and ovarian cancer risk reported positive associations (Shivappa et al, 2016; Peres et al, 2017). However, in the study that derived separate scores with and without inclusion of supplemental intake, the results were attenuated and statistically nonsignificant for the nutrient-based score calculated from dietary intake only (Shivappa et al, 2014; Peres et al, 2017), which is in line with the null findings in the current study. Limitations of the case- 
Table 1. Distribution of participant characteristics (weighted by person-years) across the entire follow-up time, in quintiles of the empirical dietary inflammatory pattern scores in the NHS (1984-2012) and the NHS-II (1991-2013) ${ }^{\mathrm{a}, \mathrm{b}}$,

\begin{tabular}{|c|c|c|c|c|c|c|}
\hline \multirow[b]{2}{*}{ Characteristic } & \multicolumn{3}{|c|}{ Nurses' Health Study (NHS) } & \multicolumn{3}{|c|}{ Nurses' Health Study II (NHS-II) } \\
\hline & Q1 & Q3 & Q5 & Q1 & Q3 & Q5 \\
\hline Average person-years & 390941 & 319212 & 234015 & 271982 & 344572 & 431470 \\
\hline Age, year & $62.1 \pm 9.5^{d}$ & $63.8 \pm 10.0$ & $61.6 \pm 9.8$ & $48.6 \pm 7.0$ & $47.1 \pm 7.2$ & $45.7 \pm 7.2$ \\
\hline History of tubal ligation, \% & 21.0 & 20.0 & 21.9 & 22.8 & 23.9 & 25.7 \\
\hline History of hysterectomy, \% & 19.1 & 22.4 & 23.3 & 7.6 & 8.6 & 9.9 \\
\hline Family history of breast or ovarian cancer, \% & 27.4 & 30.5 & 25.9 & 13.8 & 12.4 & 11.3 \\
\hline Current smoker, \% & 17.2 & 11.4 & 13.5 & 9.8 & 8.3 & 10.9 \\
\hline Parous, \% & 94.4 & 94.8 & 94.4 & 79.6 & 81.7 & 79.7 \\
\hline No. of children in parous women ${ }^{\mathbf{e}}$ & 3 & 3 & 3 & 2 & 2 & 2 \\
\hline Duration of breastfeeding in parous women, month & $6.7 \pm 10.4$ & $6.2 \pm 10.2$ & $5.6 \pm 9.8$ & $16.5 \pm 14.4$ & $15.2 \pm 14.2$ & $12.5 \pm 13.0$ \\
\hline Oral contraceptive use, ever, $\%$ & 52.7 & 49.4 & 52.7 & 86.6 & 85.8 & 84.2 \\
\hline Duration of oral contraceptive use in ever users, year & $4.1 \pm 3.9$ & $4.0 \pm 3.8$ & $4.0 \pm 3.9$ & $5.4 \pm 4.9$ & $5.5 \pm 4.9$ & $5.5 \pm 4.8$ \\
\hline Postmenopausal, \% & 81.6 & 84.2 & 78.6 & 31.2 & 23.9 & 18.4 \\
\hline Estrogen-only HT use ${ }^{f}, \%$ & 17.2 & 19.0 & 17.2 & 9.8 & 10.1 & 10.0 \\
\hline Duration of estrogen-only HT use ${ }^{g}$, year & $7.2 \pm 6.3$ & $8.0 \pm 7.0$ & $7.5 \pm 6.6$ & $3.3 \pm 3.5$ & $3.9 \pm 3.8$ & $4.2 \pm 4.1$ \\
\hline Estrogen-progestin HT usef $\%$ & 32.0 & 28.7 & 23.9 & 34.5 & 34.2 & 30.8 \\
\hline Duration of estrogen-progestin HT use ${ }^{\mathbf{g}}$, year & $5.8 \pm 4.1$ & $5.7 \pm 4.1$ & $5.2 \pm 3.7$ & $3.3 \pm 2.9$ & $3.3 \pm 2.9$ & $3.1 \pm 2.8$ \\
\hline Alcohol intake, $\mathrm{gd}^{-1}$ & $9.7 \pm 12.6$ & $4.3 \pm 7.2$ & $3.4 \pm 6.7$ & $9.6 \pm 12.5$ & $4.2 \pm 6.0$ & $2.9 \pm 4.6$ \\
\hline Total energy intake, $\mathrm{Kcal} \mathrm{d}^{-1}$ & $1780 \pm 533$ & $1668 \pm 527$ & $1814 \pm 582$ & $1947 \pm 574$ & $1756 \pm 550$ & $1857 \pm 601$ \\
\hline Used $\geqslant 1$ of 15 supplements ${ }^{h}, \%$ & 76.2 & 74.9 & 67.9 & 72.7 & 69.9 & 63.0 \\
\hline Physical activity, MET-hour per week & $20.1 \pm 23.7$ & $17.4 \pm 20.9$ & $15.5 \pm 19.2$ & $25.9 \pm 28.7$ & $21.2 \pm 24.2$ & $18.9 \pm 23.2$ \\
\hline Waist-to-hip ratio (WHR) & $0.81 \pm 0.15$ & $0.82 \pm 0.11$ & $0.84 \pm 0.11$ & $0.80 \pm 0.07$ & $0.81 \pm 0.07$ & $0.82 \pm 0.08$ \\
\hline$W H R \geqslant 0.80, \%$ & 45.7 & 53.6 & 62.0 & 48.3 & 52.3 & 61.7 \\
\hline Body mass index, $\mathrm{kg} \mathrm{m}^{-2}$ & $24.9 \pm 4.4$ & $26.3 \pm 5.1$ & $28.4 \pm 6.2$ & $25.3 \pm 5.2$ & $26.2 \pm 5.8$ & $28.3 \pm 7.2$ \\
\hline Overweight/obese, $\geqslant 25 \mathrm{~kg} \mathrm{~m}^{-2}, \%$ & 41.6 & 54.4 & 67.4 & 41.6 & 47.8 & 60.6 \\
\hline \multicolumn{7}{|c|}{ 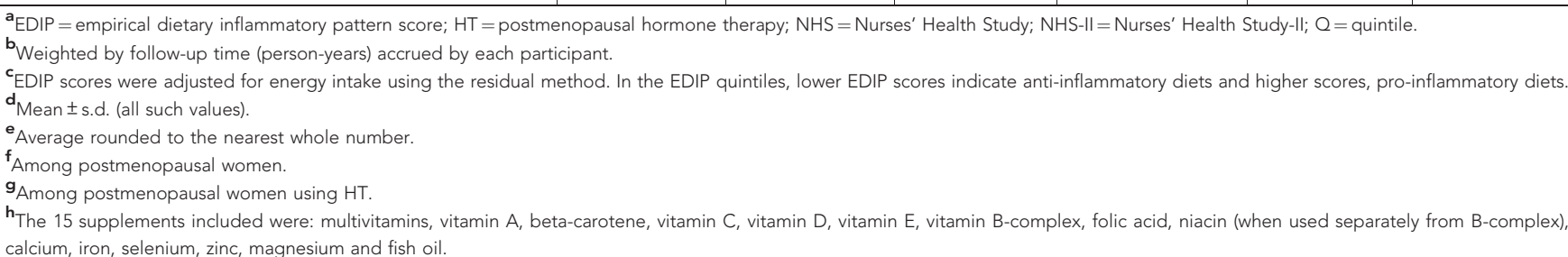 } \\
\hline
\end{tabular}

control studies include the potential for recall bias and/or reverse causation due to non-specific symptoms that may include abdominal bloating, constipation and abdominal or pelvic pain (Goff et al, 2004). Undiagnosed cancer cases suffering from nonspecific symptoms may be more likely than non-cases, to use overthe-counter medications including supplements, for symptom relief (Rock, 2007; Velicer and Ulrich, 2008). To overcome this limitation, we inserted a 2-year lag between dietary assessment and ovarian cancer diagnosis.

Owing to the prior associations of CRP with ovarian cancer risk, we hypothesised that the CRP-predictive score would be more strongly associated with risk than the EDIP, because of its correlation with CRP. However, we did not observe an association for either score. Notably, although CRP levels varied across quintiles of the EDIP score, those changes were modest and it is possible that greater changes in CRP levels are needed to increase ovarian cancer risk. Other factors, such as incessant ovulation, endometriosis, exposure to asbestos, talc powder, and pelvic inflammatory disease (Rasmussen et al, 2017), may lead to higher inflammation directly in the ovaries which could more strongly influence risk.

Major strengths of our study include using the food-based EDIP score that is correlated with levels of inflammation biomarkers associated with ovarian cancer risk. Dietary and covariate data were assessed at multiple times throughout follow-up, which allowed us to use long-term cumulative average exposures, thus reducing within-person variation. Limitations include potential measurement error in the self-reported dietary and lifestyle data, though the multiple questionnaires during follow-up approximate habitual long-term diet and reduce measurement error.

In summary, findings from this large prospective study do not support a role of dietary inflammatory potential in ovarian cancer development, thus suggesting that other factors besides diet may play important roles in influencing inflammation pathways that impact ovarian carcinogenesis.

\section{ACKNOWLEDGEMENTS}

This work was supported by National Cancer Institute grant \# P01 CA87969. Dr Fred K. Tabung was supported by National Cancer Institute grant \# K99 CA 207736. The NHS and NHS-II cohorts are supported by NIH grants: UM1 CA 186107 and UM1 CA 176726 respectively. 
Table 2. Pooled and cohort-specific hazard ratios for the association between the empirical dietary inflammatory pattern (EDIP) score and incident epithelial ovarian cancer in the NHS and NHS-II

\begin{tabular}{|c|c|c|c|c|c|c|}
\hline \multirow[b]{2}{*}{ Cohort } & \multicolumn{5}{|c|}{ EDIP quintiles (Q) } & \multirow[b]{2}{*}{$P$-trend ${ }^{\mathrm{d}}$} \\
\hline & $\begin{array}{c}\text { Q1 } \\
-18.8 \text { to }<-0.73\end{array}$ & $\begin{array}{c}\text { Q2 } \\
-0.73 \text { to }<-0.21\end{array}$ & $\begin{array}{c}\text { O3 } \\
-0.21 \text { to }<0.21\end{array}$ & $\begin{array}{c}\mathrm{Q} 4 \\
0.21 \text { to }<0.73\end{array}$ & $\begin{array}{c}\text { Q5 } \\
0.73 \text { to } 14.6\end{array}$ & \\
\hline Median EDIP score & -1.17 & -0.44 & 0.01 & 0.45 & 1.17 & \\
\hline $\begin{array}{l}\text { Pooled } \\
\text { No. of cases/person-years } \\
\text { Age, calendar time and cohort- } \\
\text { adjusted HR }(95 \% \mathrm{Cl}) \\
\text { Multivariable-adjusted HR }(95 \% \mathrm{Cl})\end{array}$ & $\begin{array}{c}218 / 682484 \\
1.00 \\
1.00\end{array}$ & $\begin{array}{c}197 / 686193 \\
0.93(0.77,1.13) \\
0.92(0.76,1.12)\end{array}$ & $\begin{array}{c}219 / 690780 \\
1.10(0.91,1.33) \\
1.07(0.89,1.30)\end{array}$ & $\begin{array}{c}188 / 694786 \\
1.00(0.82,1.22) \\
0.98(0.80,1.19)\end{array}$ & $\begin{array}{c}167 / 700271 \\
1.04(0.84,1.27) \\
0.99(0.80,1.22)\end{array}$ & $\begin{array}{l}0.64 \\
0.97\end{array}$ \\
\hline $\begin{array}{l}\text { Nurses' Health Study (NHS) } \\
\text { No. of cases/person-years } \\
\text { Age, calendar time and cohort- } \\
\text { adjusted HR ( } 95 \% \mathrm{Cl}) \\
\text { Multivariable-adjusted HR }(95 \% \mathrm{Cl})\end{array}$ & $\begin{array}{c}173 / 390941 \\
1.00 \\
1.00\end{array}$ & $\begin{array}{c}153 / 351940 \\
0.94(0.75,1.17) \\
0.93(0.75,1.16)\end{array}$ & $\begin{array}{c}167 / 319212 \\
1.13(0.91,1.39) \\
1.12(0.90,1.38)\end{array}$ & $\begin{array}{c}135 / 285323 \\
1.02(0.82,1.28) \\
1.02(0.81,1.29)\end{array}$ & $\begin{array}{c}103 / 234015 \\
1.02(0.80,1.30) \\
1.03(0.80,1.32)\end{array}$ & $\begin{array}{l}0.47 \\
0.46\end{array}$ \\
\hline $\begin{array}{l}\text { Nurses' Health Study II (NHS-II) } \\
\text { No. of cases/person-years } \\
\text { Age, calendar time and cohort- } \\
\text { adjusted HR ( } 95 \% \mathrm{Cl}) \\
\text { Multivariable-adjusted HR (95\% Cl) }\end{array}$ & $\begin{array}{c}45 / 271982 \\
1.00 \\
1.00\end{array}$ & $\begin{array}{c}44 / 310869 \\
0.91(0.60,1.38) \\
0.90(0.59,1.36)\end{array}$ & $\begin{array}{c}52 / 344572 \\
1.01(0.67,1.50) \\
0.98(0.66,1.47)\end{array}$ & $\begin{array}{c}53 / 378971 \\
0.94(0.63,1.40) \\
0.89(0.59,1.34)\end{array}$ & $\begin{array}{c}64 / 431470 \\
1.04(0.71,1.53) \\
0.93(0.63,1.39)\end{array}$ & $\begin{array}{l}0.80 \\
0.37\end{array}$ \\
\hline $\begin{array}{l}\text { Abbreviations: } \mathrm{Cl}=\text { confidence interval; EDIP } \\
{ }^{a_{E}} \text { EDIP scores were adjusted for energy intak } \\
{ }^{b} \text { EDIP quintiles were based on the distribut } \\
{ }^{c} \text { Cox proportional hazards models were usec } \\
\text { cancer or ovarian cancer, duration of oral co } \\
\text { supplements used; models were further strat } \\
\text { beta-carotene, vitamin C, vitamin D, vitamin } \\
{ }^{d} \text { Continuous residual-adjusted EDIP scores }\end{array}$ & $\begin{array}{l}\text { sing the residual method. } \\
\text { in the pooled study popul } \\
\text { rall analyses. Analyses wer } \\
\text { aceptive use, menopausal } \\
\text { d by cohort in the pooled } \\
\text { vitamin B-complex, folic ac } \\
\text { e used to test for linear tre }\end{array}$ & $\begin{array}{l}\text { on. } \\
\text { the EDIP quintiles, lower } \\
\text { tus, postmenopausal horn } \\
\text { alysis. Fifteen supplement } \\
\text { niacin (when used separ } \\
\text { across EDIP quartiles, ac }\end{array}$ & $\begin{array}{l}\text { scores indicate anti-i } \\
\text { time, and were adjuste } \\
\text { duration and type, th } \\
\text { from B-complex), cal }\end{array}$ & $\begin{array}{l}\text { or parity, duration of } \\
\text { l ligation, hysterector } \\
\text { e 'number of supplen } \\
m \text {, iron, selenium, zin }\end{array}$ & $\begin{array}{l}\text { astfeeding, family his } \\
\text { body mass index, an } \\
\text { ts used': multivitamir } \\
\text { magnesium and fish }\end{array}$ & $\begin{array}{l}\text { natory diets. } \\
\text { ory of breast } \\
\text { d number of } \\
\text { s, vitamin A, } \\
\text { il. }\end{array}$ \\
\hline
\end{tabular}

Table 3. Pooled hazard ratios for the association between the empirical dietary inflammatory pattern (EDIP) and incident epithelial ovarian cancer by histologic subtype and tumour aggressiveness in the NHS and NHS-II ${ }^{a, b, c}$

\begin{tabular}{|c|c|c|c|c|c|c|c|}
\hline \multicolumn{8}{|c|}{ EDIP quintiles } \\
\hline Ovarian cancer subtype & Quintile 1 & Quintile 2 & Quintile 3 & Quintile 4 & Quintile 5 & $P$-trend ${ }^{d}$ & $P$-heterogeneity ${ }^{e}$ \\
\hline $\begin{array}{l}\text { Serous and poorly differentiated } \\
\text { ( } n \text { cases }=637 \text { ) }\end{array}$ & 1.00 & $0.99(0.78,1.26)$ & $1.16(0.92,1.47)$ & $1.00(0.78,1.29)$ & $0.98(0.74,1.28)$ & 0.78 & 0.52 \\
\hline Non-serous $(n$ cases $=244$ ) & 1.00 & $0.76(0.51,1.13$ & $0.83(0.56,1.23)$ & $0.89(0.60,1.32)$ & $0.97(0.64,1.42)$ & 0.85 & \\
\hline Rapidly fatal ${ }^{f}(n$ cases $=330$ ) & 1.00 & $0.86(0.62,1.19)$ & $0.89(0.64,1.24)$ & $1.04(0.751 .45)$ & $0.91(0.63,1.32)$ & 0.72 & 0.63 \\
\hline Less aggressive $^{f}(n$ cases $=476)$ & 1.00 & $0.96(0.73,1.28)$ & $1.18(0.90,1.55)$ & $1.02(0.76,1.37)$ & $1.10(0.82,1.49)$ & 0.62 & \\
\hline \multicolumn{8}{|c|}{ 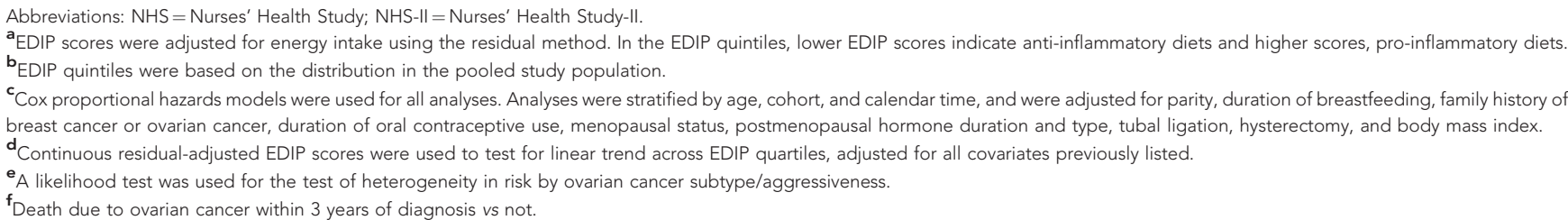 } \\
\hline
\end{tabular}

\section{CONFLICT OF INTEREST}

The authors declare no conflict of interest.

\section{REFERENCES}

Crane TE, Khulpateea BR, Alberts DS, Basen-Engquist K, Thomson CA. (2014) Dietary intake and ovarian cancer risk: a systematic review. Cancer epidemiol biomarker prev 23(2): 255-273.

Faber MT, Kjær SK, Dehlendorff C, Chang-Claude J, Andersen KK, Høgdall E, Webb PM, Jordan SJ. Australian Cancer Study (Ovarian Cancer); Australian Ovarian Cancer Study GroupRossing MA,
Doherty JA, Lurie G, Thompson PJ, Carney ME, Goodman MT, Ness RB, Modugno F, Edwards RP, Bunker CH, Goode EL, Fridley BL, Vierkant RA, Larson MC, Schildkraut J, Cramer DW, Terry KL, Vitonis AF, Bandera EV, Olson SH, King M, Chandran U, Kiemeney LA, Massuger LF, van Altena AM, Vermeulen SH, Brinton L, Wentzensen N, Lissowska J, Yang HP, Moysich KB, Odunsi K, Kasza K, Odunsi-Akanji O, Song H, Pharaoh P, Shah M, Whittemore AS, McGuire V, Sieh W, Sutphen R, Menon U, Gayther SA, Ramus SJ, Gentry-Maharaj A, Pearce CL, Wu AH, Pike MC, Risch HA, Jensen A. Ovarian Cancer Association Consortium (2013) Cigarette smoking and risk of ovarian cancer: a pooled analysis of 21 case-control studies. Cancer causes and control 245(10): 1007/s10552-1013.

Feskanich D, Rimm EB, Giovannucci EL, Colditz GA, Stampfer MJ, Litin LB, Willett WC (1993) Reproducibility and validity of food intake 
measurements from a semiquantitative food frequency questionnaire J Am Diet Assoc 93(7): 790-796.

Goff BA, Mandel LS, Melancon CH, Muntz HG (2004) Frequency of symptoms of ovarian cancer in women presenting to primary care clinics. JAMA 291(22): 2705-2712.

Hu FB, Rimm E, Smith-Warner SA, Feskanich D, Stampfer MJ, Ascherio A, Sampson L, Willett WC (1999) Reproducibility and validity of dietary patterns assessed with a food frequency questionnaire. Am J Clin Nutr 69(2): 243-249.

Peres LC, Bandera EV, Qin B, Guertin KA, Shivappa N, Hebert JR, Abbott SE, Alberg AJ, Barnholtz-Sloan J, Bondy M, Cote ML, Funkhouser E, Moorman PG, Peters ES, Schwartz AG, Terry PD, Camacho F, Wang F, Schildkraut JM (2017) Dietary inflammatory index and risk of epithelial ovarian cancer in African American women. Int $j$ cancer 140(3): 535-543.

Poole E, Lee IM, Ridker PM, Buring JE, Hankinson SE, Tworoger SS (2013a) A prospective study of circulating C-reactive protein,interleukin-6, and tumor necrosis factor $\alpha$ receptor 2 levels and risk of ovarian cancer. Am J Epidemiol 178(8): 1256-1264.

Poole EM, Merritt MA, Jordan SJ, Yang HP, Hankinson SE, Park Y, Rosner B, Webb PM, Cramer DW, Wentzensen N, Terry KL, Tworoger SS (2013b) Hormonal and reproductive risk factors for epithelial ovarian cancer by tumor aggressiveness. Cancer epidemiol biomarker prev 22(3): 429-437.

Rasmussen CB, Kjaer SK, Albieri V, Bandera EV, Doherty JA, Høgdall E, Webb PM, Jordan SJ, Rossing MA, Wicklund KG, Goodman MT, Modugno F, Moysich KB, Ness RB, Edwards RP, Schildkraut JM, Berchuck A, Olson SH, Kiemeney LA, Massuger LF, Narod SA, Phelan CM, Anton-Culver H, Ziogas A, Wu AH, Pearce CL, Risch HA, Jensen A. on behalf of the Ovarian Cancer Association Consortium (2017) Pelvic inflammatory disease and the risk of ovarian cancer and borderline ovarian tumors: a pooled analysis of 13 case-control studies. Am J Epidemiol 185(1): 8-20.

Rock CL (2007) Multivitamin-multimineral supplements: who uses them? Am J Clin Nutr 85(1): 277S-279S.

Shivappa N, Hébert JR, Rosato V, Rossi M, Montella M, Serraino D, La Vecchia C (2016) Dietary inflammatory index and ovarian cancer risk in a large Italian case-control study. Cancer Causes Control 27(7): 897-906.

Shivappa N, Prizment AE, Blair CK, Jacobs Jr DR, Steck SE, Hébert JR (2014) Dietary inflammatory index and risk of colorectal cancer in the Iowa Women's Health Study. Cancer Epidemiol Biomarker Prev 23(11): 2383-2392.
Siegel RL, Miller KD, Jemal A (2017) Cancer statistics, 2017. Cancer J Clin 67(1): 7-30.

Stampfer MJ, Willett WC, Speizer FE, Dysert DC, Lipnick R, Rosner B, Hennekens CH (1984) Test of the National Death Index. Am J Epidemiol 119(5): 837-839.

Tabung FK, Smith-Warner SA, Chavarro JE, Fung TT, Hu FB, Willett WC, Giovannucci EL (2017) An empirical dietary inflammatory pattern score enhances prediction of circulating inflammatory biomarkers in adults. J Nutr; e-pub ahead of print 28 June 2017; doi:10.3945/jn.117.248377.

Tabung FK, Smith-Warner SA, Chavarro JE, Wu K, Fuchs SF, Hu FB, Chan AT, Willett WC, Giovannucci EL (2016) Development and validation of an empirical index of dietary inflammatory potential. J Nutr 146(8): 1560-1570.

Tworoger SS, Huang T (2016) Obesity and ovarian cancer. Cancer Res 208: $155-176$.

Velicer CM, Ulrich CM (2008) Vitamin and mineral supplement use among US adults after cancer diagnosis: a systematic review. J Clin Oncol 26(4): 665-673.

Wang M, Spiegelman D, Kuchiba A, Lochhead P, Kim S, Chan AT, Poole EM, Tamimi R, Tworoger SS, Giovannucci E, Rosner B, Ogino S (2016) Statistical methods for studying disease subtype heterogeneity. Stat Med 35(5): 782-800.

Willett W, Sampson L, Stampfer MJ, Rosner B, Bain C, Witschi J, Hennekens CH, Speizer FE (1985) Reproducibility and validity of a semiquantitative food frequency questionnaire. Am J Epidemiol 122(1): 51-65.

Xie J, Poole EM, Terry KL, Fung TT, Rosner BA, Willett WC, Tworoger SS (2014) A prospective cohort study of dietary indices and incidence of epithelial ovarian cancer. J Ovarian Res 7: 112.

Zeng F, Wei H, Yeoh E, Zhang Z, Ren ZF, Colditz GA, Tworoger SS, Su X (2016) Inflammatory markers of CRP, IL6, TNF $\alpha$, and soluble TNFR2 and the risk of ovarian cancer: a meta-analysis of prospective studies. Cancer Epidemiol Biomarker Prev 25(8): 1231-1239.

This work is published under the standard license to publish agreement. After 12 months the work will become freely available and the license terms will switch to a Creative Commons AttributionNonCommercial-Share Alike 4.0 Unported License.

Supplementary Information accompanies this paper on British Journal of Cancer website (http://www.nature.com/bjc) 